\title{
Counterbalancing the Asymmetric Information Paradigm on High-Value Low-Frequency Transactions
}

\author{
Mark Hoksbergen \\ University of Auckland \\ m.hoksbergen@auckland.ac.nz \\ Gabrielle Peko \\ University of Auckland \\ g.peko@auckland.ac.nz
}

\author{
Johnny Chan \\ University of Auckland \\ jh.chan@auckland.ac.nz \\ David Sundaram \\ University of Auckland \\ d.sundaram@auckland.ac.nz
}

\begin{abstract}
This paper examines the impact of asymmetric information on the purchase of high-value infrequently traded assets. If a high-value asset is infrequently traded in a market its valuation becomes less predictable and more tension can exist between the vendor and the purchaser. Often the vendor possesses more knowledge of the asset, which leads to an asymmetric information paradigm between the two parties, nurturing a dark side of information and knowledge management. Using the New Zealand real estate industry as the context of a design science research study, a purchase decision process model for high-value infrequently traded assets has been developed. It aims to support the novice real estate purchaser to realise the potential pitfalls they should avoid. The study also calls for a unified system with codifiable, explicit information that can be used by all stakeholders in high-value infrequently transactions. Thus reducing the asymmetric information imbalance between vendor and purchaser.
\end{abstract}

\section{Introduction}

Trading goods is part of human existence and has always created tension between vendor and purchaser. This tension is particularly apparent in high-value assets with information that is hard to ascertain. The misuse of asymmetric information has been the cornerstone for many a charlatan and has allowed snake oil to be pedalled throughout history.

A purchaser that infrequently purchases a high-value asset through an intermediary is at a particular disadvantage. They face an increased risk of forming a purchase decision based on information that can't be relied on to adjust their assumptions or actions [5]. The infrequency of trading and asymmetric information disproportionately advantages the vendor (or intermediary) in the sale of a high-value asset with specialised proprietary knowledge.

Furthermore, the vendor can also take advantage of the noise in the communication channel [19]. When purchase decisions are affected by such noise and are not verifiable, it can lead to a long-lasting financial impact and could be hard to revert a purchase legally. Most governments have laws in place to prevent blatant misuse of asymmetric information in trading. For example, the United States has a "Lemon Law" (Magnuson-Moss Warranty Act, 1975) that protects the purchaser from defective goods and enforcing implied warranties. New Zealand has the Fair Trading Act (1986) to protect consumers. However, it is in the margins of the law, which are hard to prove, where much financial hardship could occur. Besides, there are further problems with acquiring the necessary information, such as their codifiability, comprehensibility, reliability, and relevancy [15]. To resolve these issues, it naturally calls for a knowledge base filled with well-defined, historically complete, trustworthy and meaningful, timestamped records representing each of the high-value infrequently traded assets.

Over the past 150 years, dating back to the industrial revolution, we have used a linear economic model where goods are manufactured from raw materials and sold, used and thrown away. In the last 15 years there is a groundswell for moving to a circular economy where the added value of products is held for as long as possible to reduce waste. Such a concept re-imagines how the material flows through the economy might be closed [18]. This should apply to data as well; critical information associated with a high-value infrequently traded asset is not just gathered for one time and discarded, instead it remains in the knowledge base for 
as long as possible ensuring the proverbial wheel is not reinvented many times.

In this paper, we first delve into understanding information asymmetry and knowledge. We then look at information asymmetry of high-value infrequently traded assets in the context of the real estate industry. We conduct our study using New Zealand as an exemplar. We develop practical models that could be generalised to other industries to reduce information asymmetry between vendor and purchaser. Finally, we discuss how a purchaser could benefit from these models.

\section{Information Asymmetry and Knowledge}

Problems relating to information asymmetry going back to the eighteenth century have been discussed. According to Stiglitz [20] information is not perfect, obtaining information is costly, and there is always a degree of information asymmetry among competitive markets. The extent of this is associated with actions of individuals and organisations. Information asymmetry in a competitive market gives an advantage to one party while disadvantaging the other.

The literature is clear on the negative outcomes associated with asymmetric information particularly for the purchaser. However, there is little known about the role of asymmetric information in transactions of highvalue low-frequency assets, and how it could affect the purchaser decision process. This is the gap in the literature that we plan to ameliorate.

The study of information and knowledge covers a vast domain of literature as it applies to a large number of academic disciplines. The basic definition of knowledge often used among epistemologists is that of Plato, describing a proposition that knowledge is present when truth intersects with belief and becomes a justified belief. Ackoff [1] argues that the primary goal of gaining knowledge is to progress towards wisdom. Knowledge is obtained by formalising facts and ideas, processing them into information, and converting them to knowledge [8]. Tuomi [21] describes contextualisation as a driving force to understand the data to knowledge transformation. Along the same lines, Carpenter and Cannady [7] add environment as a prerequisite to data, and vision as an outcome of wisdom. Most conceptual models of knowledge are linear; perhaps a circular model would be more appropriate, especially if understanding and context are continuously changing and affecting each other as is the case of high-value infrequent traded assets. There is also a lack of practicality and measurability [12] among those conceptual models for our purpose.
Furthermore, knowledge is either tacit or explicit [3]. Nonaka and Takeuchi [17] define tacit knowledge as "personal knowledge embedded in individual experience and involves intangible factors such as personal beliefs, perspective and value systems," and explicit knowledge could be expressed in code and is not subject to multiple interpretations. Tacit knowledge is either "has not" been formalised or "could not be" formalised. Once knowledge is formalised, it becomes explicit [13]. In the context of purchasing high-value infrequently traded assets, the information asymmetry could appear within the realm of tacit knowledge. The unverifiable statements made to a purchaser, for instance, are hard to verify and even harder to rectify after a purchase. This leads us to the question of whether we could reduce the amount of tacit knowledge and increase the amount of explicit knowledge, held on a property for instance, and how it could be managed and shared.

Knowledge management systems often focus on the sharing of information within an organisation. According to Brooking [6], knowledge management is the process by which we manage human-centred assets. The function of knowledge management is to guard and grow knowledge owned by individuals and, where possible, transfer the asset into a form where others can more readily share it. But the difficulty faced by knowledge management systems is to codify tacit knowledge into explicit knowledge [9].

If knowledge exists ultimately within individuals, and individuals are participating simultaneously in multiple group processes to make and execute critical decisions, then a fundamental of "managing knowledge" must be to build some degree of shared context [10]. Alavi and Leidner [3] study the objective of knowledge management systems to support the creation, transfer, and application of knowledge. After creating a shared context, translating tacit knowledge into explicit knowledge, and building a reliable knowledge management system, there will be a need for presenting the information in a uniform way that can be understood by a large segment of the population relying on them to make educated decisions.

Selling and buying high-value infrequently traded assets involving multi-stakeholders is seen as a finite, zero-sum game. Within this context, we focus on the New Zealand real estate industry as a domain with conflicting objectives among vendors, intermediaries and purchasers. And we highlight the processes that involve counterbalancing information asymmetry on these high-value low-frequency transactions. While the focus is on the New Zealand real estate industry, these issues arise in many high-value low-frequency asset transactions in various domains throughout the world. 


\section{The Study}

We scope our investigation to the New Zealand real estate industry as it has several unique features. For instance, nearly a third of New Zealanders use real estate as one of their primary, long-term, investment strategies. To compound matters, a purchaser of real estate in New Zealand does not have a dedicated agent to work on their behalf, rather they depend on the vendor's agent to assist with the transaction.

In our study, we purposefully focused on the novice residential real estate purchaser and how, potentially, they could be disadvantaged from making purchase decision with information asymmetry in high-value infrequently traded transactions. We identified six types of stakeholders in the real estate industry and used an interpretive lens as our philosophical assumption. Initially, we conducted semi-structured interviews to collect empirical data on how experienced real estate agents would buy a property for themselves. We also interviewed four experienced developers to gain an understanding of how decisions were made for buying land or property. This empirical data was used to create a Model of Communication and a Purchaser Decision Process Model to support a novice purchaser buying real estate. These artefacts were then assessed and analysed using a focus group, resulting in a further refined Model of Communication (Figure 1) and the Purchaser Decision Process Model (Figure 2). Next, two rounds of semi-structured interviews were conducted with two employees of a real estate agency in New Zealand, both having over 20 years of experience. One of the interviewees had sold over 400 residential properties while the other was a licensed real estate agent who handled the administrative processes of finalising transactions. The initial interviews covered the entire process of purchasing real estate in New Zealand. Subsequently, we divided this process into six stages and it is introduced in a later section. The primary aim of the interviews was to identify all the stakeholders involved in each stage of the real estate purchasing process and the questions that needed to be addressed by a purchaser at each stage. The second round of interviews was held with the same interviewees aiming to classify all the questions into hard and soft criteria. The criteria were explained to the candidates as measurable (tacit) or non-measurable answers (explicit). The hard and soft criteria were then synthesised into the two models (Model of Communication and the Purchaser Decision Process Model) as tacit and explicit information. With regard to the Purchaser Decision Process Model (Figure 2), we translated the findings and developed a roadmap to purchasing real estate in New Zealand (Figure 3). These artefacts, namely the model and roadmap, were then further refined and validated by a focus group that met twice. The focus group consisted of six members with diverse backgrounds ranging from novice to experienced investors aged between 24 to 52 . These members also had a mixture of cultural backgrounds and experiences of real estate purchases outside of New Zealand.

The semi-structured interviews with the domain experts and the considerations from the series of focus groups resulted in a model of communication and a decision process roadmap that could be practically implemented to support novice real estate purchasers to ask the right questions when purchasing real estate.

\section{Research Artefacts}

In New Zealand, there are multiple stakeholders involved in collecting information about a real estate property. There are also conflicting objectives among the government, council, specialist, and real estate organisation. There is a discrepancy between property files held by the council and the Land Information Memorandum (LIM). A purchaser would typically hire specialists such as a building expert, engineer, surveyor and others during the due diligence period. They collect enormous amounts of data related to a property without any obligation to register this information. If the sale does not result in an unconditional offer, the information collected will be lost. Multiple specialists with different outcomes can sometimes perform these information collection exercise multiple times for the same property.

There is also much-biased information given on a verbal basis, often through real estate agents. An example could be "the house has just been painted." The information could be more value-added to a purchaser if the company name is mentioned, the date it happened, the warranty on the kind of paint that was used and the cost of the paint job. Interestingly, the majority of information about a property is often given verbally by a real estate agent. Furthermore, there is a possibility of adding an "owners" database to a property file that could be linked to the LIM and therefore become part of the property file itself.

It has also been established by Allmon and Grant [4] that as the principal intermediary, the real estate agent, does not always have the best interest in mind for both the purchaser and the vendor. The primary driver for a real estate agent is the actual property sale. Their key performance indicators (KPI) are number of listings, number of potential purchasers, and sales volume. Hence, they do not always align with the best interests of purchasers.

Purchasing and selling real estate in New Zealand is becoming more complex. New rules and regulations are introduced and more and more of the responsibilities are 
delegated to the real estate agent and the purchaser. Once the initial price negotiation is completed there is often a deadline to finish the due diligence of the sale by the purchaser.

The real estate industry can be identified by multiple stakeholders with conflicting objectives in a finite, zerosum game typically involving many intermediaries to obtain a satisfactory transaction between a vendor and a purchaser. For a purchaser, there is the added complexity of finding all the right documents needed to make an informed decision on a real estate transaction and conduct proper due diligence. Currently, there is a property file that can be requested from the council with all the consent notices, forms, code of compliances and reports they have on file for a particular property. This is summarised in a LIM and can be purchased for approximately NZD\$200 to NZD\$400 and gives consents, legal description, lands use, zoning, utilities. The property file and LIM do not always correlate and sometimes have critical information missing.

The information presented in a LIM has a legal caveat that the council is not liable and cannot guarantee the accuracy of the information. Furthermore, the LIM is not printed with any page numbers leaving it susceptible to manipulation. A purchaser then needs to obtain a title that gives caveats, covenants, mortgages, etc., lodged against the title. There are multitudes of reports that can be requested. Moisture report, asbestos report, electrician report, builders report, soil test, archaeological test, drainage report, geo-tech report, valuation report, etc. These reports are paid for by a purchaser and are not reported back to the council. This can result in the same report being requested multiple times and sometimes overlooked completely. In buying a property, there is a lot of smaller indicators that could assist a sale of real estate. These are often verbally transmitted and after a sale is completed, possibly lost. There is a crucial link of information missing in land and real estate transactions, and that is private information known to the vendor and not necessarily legally required to submit. This information could paint a full picture of the property being sold. This information is diverse and could range from the date a new hot-water cylinder was installed, a recent repaint of a house, the paint used, the new locks and alarm system, solar systems, etc. This information would have a date, installers name, price, and possible warranty. This would also ensure that warranties are transferable to the new owner. This information would also improve the code of conduct for a large number of trades as a warranty, and their name is now attached to the property. Figure 1 illustrates the information asymmetry between a purchaser and vendor of a real estate transaction by adapting Shannon and Weaver model of communication [19].

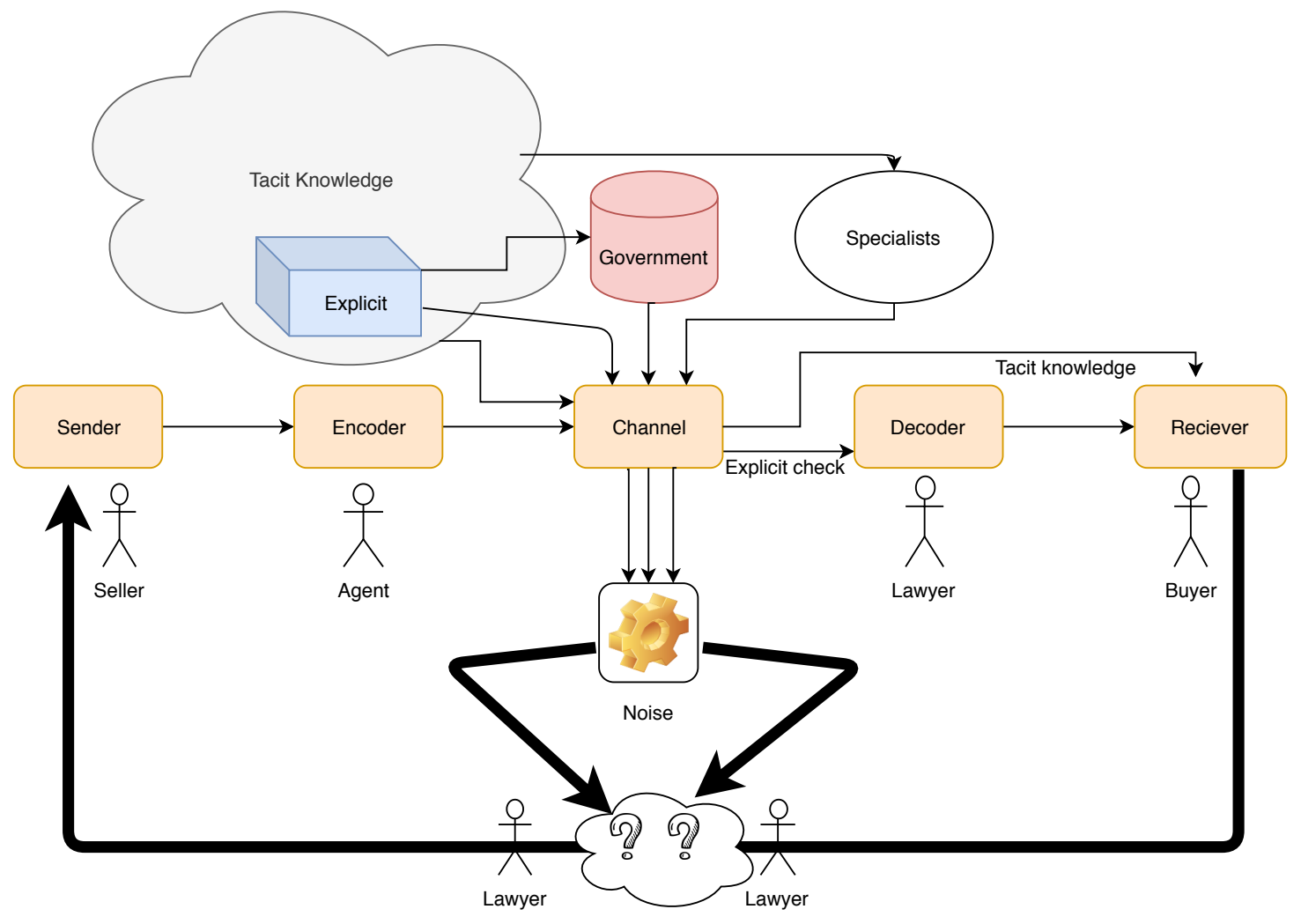

Figure 1. Model of communication for a real estate transaction 
Akerlof's seminal paper [2] states that information asymmetry is prevalent in second-hand markets. The vendor who has owned or used their asset for a while are better informed about the state of their asset than the purchaser. Since a purchaser usually cannot observe an asset's real quality, an unscrupulous vendor could be incentivised to sell at an overinflated price.

We have divided the process of purchasing real estate into six specific stages. We designed the process stages using two steps. The first step adopts the hypothetical model created by Grum and Kobal Grum [11] that related to the psychological factors involved in the decision-making to buy real estate. The second step involves synthesising the words used in the semistructured interviews.

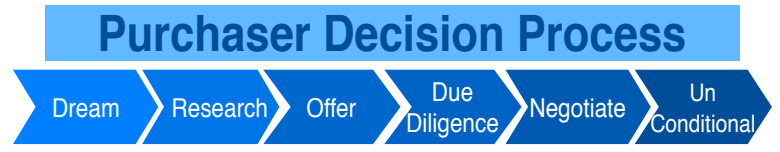

\section{Figure 2. The purchaser decision process}

These six stages are not siloed, and in some situation they could have overlaps. For example, dreaming and researching for potential properties and locations are not clearly defined and can easily transfer between the two categories, but overall it establishes the thought process of seasoned professionals in real estate.

\subsection{Dream}

At this stage, a purchaser is deciding where to buy. From the perspective of a purchaser, the stakeholders involved are local residents and real estate agents. We refer to this as the dream stage. Getting an idea of area, township, whether there is employment, the type of neighbourhood, and a rough price indication. Generally, a feel for the area is based on a subset of emotions. In general key aspects/issues of importance are: local area, feel, medical centre, township activity, transportation, community offering, shop, cafe, school, neighbourhood, and employment.

\subsection{Research}

This stage involves a more focused approach. A purchaser will find out their exact price range, dictated by financial institutions and their own financial sense. A real estate agent will provide specific information on why buying in the area is beneficial.

By now, a purchaser will be narrowing down to a specific property and discovering growth, employment, infrastructure and opportunities in the area like health care facilities, school zoning, and internet connectivity.
Once a potential choice is narrowed down more detailed information is required, including section size, government valuation, rates, development in the immediate vicinity, current market analysis, storm water and sewage. As one progresses on the research journey it becomes clear that most of the information that is required to take an informed decision is tacit rather than explicit (Table 1). This represents the dark side of many high-value low-frequency asset purchases which are made with insufficient verifiable knowledge.

\subsection{Offer}

The initial offer is drafted by the real estate agent and will nearly always have a few conditions in them. The most common are LIM, finance, and builders report. There are a host of other conditions that can be drawn up depending on the specific circumstances. There will also be a date set for the offer to go unconditional. At this stage, the vendor's and purchaser's lawyers are involved. The offer will have a final date set, and this will give the time to resolve all conditions set in the offer. An agreed deposit will be made into a trust account. The basic issues/requirements that need to be addressed before one can make an offer are: negotiate price and have finance organised, requesting the official title, fulfilling the anti-money laundering (AML) requirement, adding personal conditions to the sale, setting the due diligence period and pay the negotiated deposit. The dark side in this stage is the uncertainty of the verifiability of the information given.

\section{Table 1. Tacit vs explicit knowledge in the research phase}

\begin{tabular}{|l|l|}
\hline Tacit & Explicit \\
\hline View & Price Range \\
Growth & Zoning \\
Opportunity & School District \\
Future Development & Healthcare \\
Infrastructure & Restriction \\
Limitation & Storm Water \\
Lifestyle & Internet Coverage \\
& Rates \\
& CMA \\
& Government Valuation \\
& Sewage/Septic \\
\hline
\end{tabular}

\subsection{Due Diligence}

This is the most important stage in a high-value lowfrequency transaction. This is where we need counterbalance asymmetric information so that we can uncover and address possible risks in the transaction. 
This last stage in gathering all the relevant information pertaining to a property could be a costly and timeconsuming exercise, depending on the number of reports needed or requested. At this stage, all the stakeholders are involved. To organise finance, legal descriptions on a title, specific questions on chattels and specialists reports on the property. If the transaction does not proceed for any reason, the information collected from these reports will be lost, due to the fact that the potential purchaser has paid for and owns them. This gives the vendor the possibility to re-list the property with the same issues as before without needing to disclose or mitigate any problems identified by those reports. The most common reports requested in the due diligence stage are listed in Table 2. These reports often verify the tacit information and transform them into explicit information.

\subsection{Negotiate}

Depending on the results of the Due Diligence stage, there are only three remaining options. Walk away from the deal, renegotiate, or sign the deal. Once signed the offer becomes unconditional.

\subsection{Unconditional}

At this stage the transaction is finalized. The deposit is transferred into a trust account, and the title and deposit redistributed (minus lawyer, real estate fees, and rates expenses). The electricity, water, gas, phone, keys, and chattels are transferred into the new owner's name. Finally, the sale price is recorded with the council.

\section{Table 2. Reports requested during Due- diligence phase}

\begin{tabular}{|l|l}
\hline LIM Report & Valuation Report \\
Builders Report & Archaeological Report \\
Title Requisition & Asbestos Report \\
Geo-Tech Report & Swimming Pool Report \\
Surveying & Methamphetamine \\
Valuation & Drainage Report \\
Moisture Report & Landscape Report \\
Electrical Report & 221 Report Council \\
Soil Testing & Insulation Report \\
\hline
\end{tabular}

\section{Findings}

The challenges faced by a purchaser is that explicit information is often specialised propriety information and derived from a multiplicity of sources with conflicting objectives. Tacit information is often verbally transmitted by the vendor or agent. Due to the low frequency in purchases, tacit knowledge is used to increase the asymmetric knowledge gap between a novice purchaser and experienced agent. The study has contributed to the literature in two ways. First, it has created a framework to guide novice purchasers of real estate in New Zealand. Second, the study contributes by adding a layer of coding ability that could be further developed by the real estate industry. The synthesised Purchaser Decision Process Roadmap (Figure 3) could benefit a purchaser by guiding him/her in the kind of questions that need to be asked when purchasing real estate in New Zealand. The further sub-categorising of the questions into tacit and explicit would give the possibility of partly standardising information and implementing knowledge management systems into the sales process.

\section{Discussion}

Our model built for real estate in New Zealand could potentially be generalised for real estate in other places, or even other high-value infrequently traded assets, such as the purchase of a diamond engagement ring. Typically, purchasing a diamond engagement ring is a low-frequency purchase and the information that needs to be gleaned before making an informed decision is information regarding: the diamond's clarity, cut, and carat, the country of origin, the designer of the ring, the price, new or second-hand, fashion, etc. There is a large discrepancy between the knowledge of a jeweller and the knowledge of a novice purchaser, each with conflicting objectives. If we could codify and categorise the information, this would lead to a better informed purchaser and a reduced likelihood of paying a premium for example, due to their lack of knowledge. Although there are similarities between purchasing a diamond ring and a property, the long term financial impact is much greater in the latter.

High-value infrequently traded assets are often purchased through an intermediary and sometimes checked by a third party. There is a disincentive for the vendor, or the agent, to codify information as it is currently not beneficially to the transaction. In other words, the vendor and/or agent benefits from the asymmetric information and can leverage it to potentially sell at a higher price. Due to the infrequency of trading, it is time-consuming and costly for a purchaser to gain the level of knowledge required to make an informed decision. Most of the stakeholders in the transaction are highly organised: lawyers, real estate agencies, financial institutions, councils and specialised advisors (surveyors, geo-tech, etc.) and nearly all have caveats releasing them on any inaccuracy of the information provided. Unlike a purchaser who has little legal recall if they purchased a "proverbial lemon." The 
application of blockchain could be a potential solution to store verifiable information onto a permissioned distributed ledger with a shared database. This would address information asymmetry in various ways. First, all information would be timestamped giving the data a historical context. Second, the information would be verifiable and only entered through trusted nodes. Third, it would give a legal recall to a purchaser if the information used to make a purchase decision was wrong. And, finally, information that previously had been collected does not have to be reiterated saving time and money.

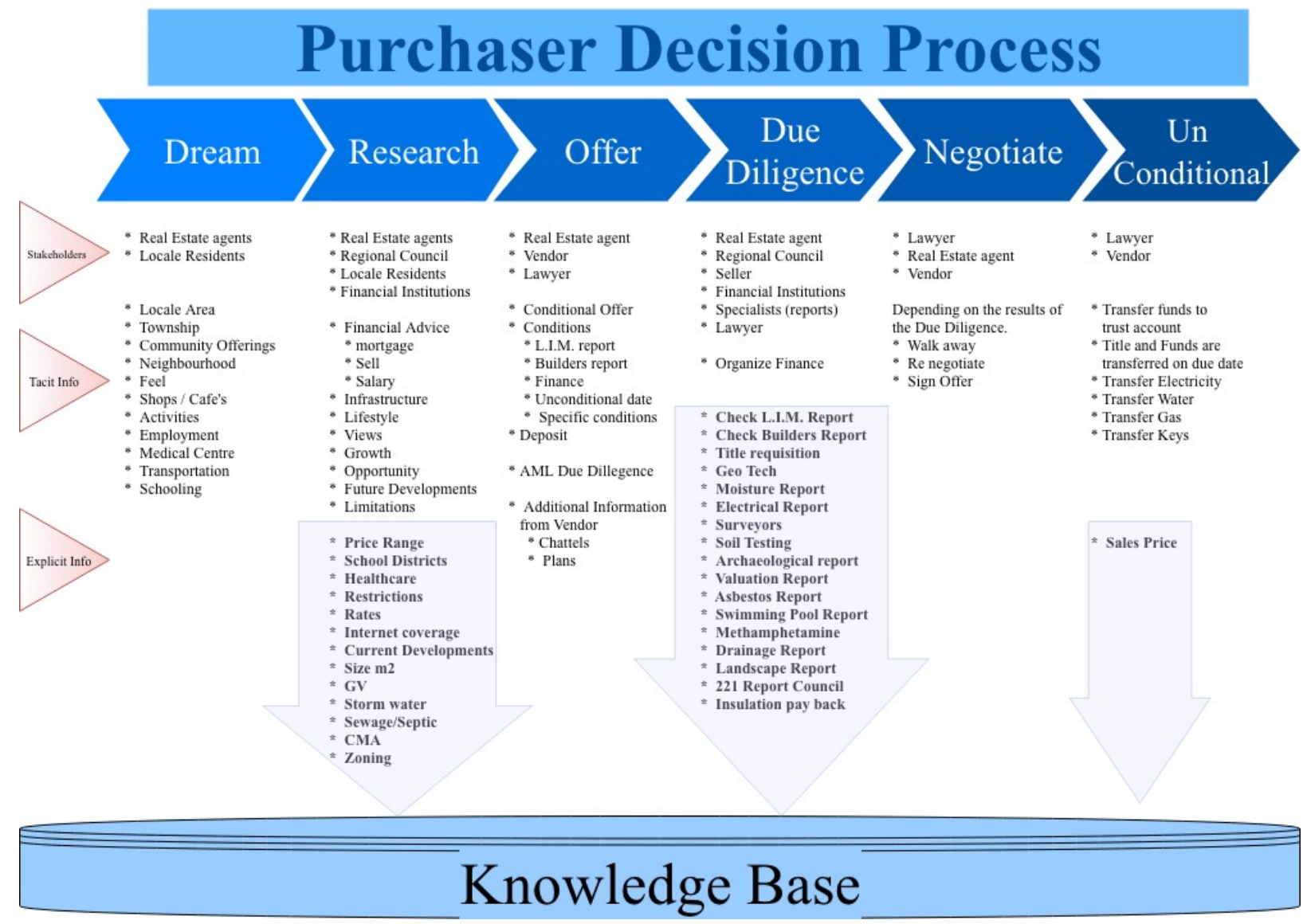

Figure 3. The purchaser decision process roadmap

\section{Limitations}

This study is limited in several ways. It could be argued that the number of interviews held to reach a conclusion are less than ideal. Although according to Myers [16] the representation of the various voices within a group is more important than the sample size. Also, the sample size should be dictated by the saturation point of new insights, not by the number of interviews. Our view, however, is that the saturation point in this paper has not been reached and that the geographical spread, the interviews were held within one real estate company, impacts the generalisability of the research. Although we believe the methodology can be extrapolated to other industries dealing with highvalue infrequently traded assets, this is not conclusive.
Hence, more stakeholders from a wider range within the real estate industry could be questioned resulting in a more in-depth picture. In addition, the feedback gleaned from the focus group identified a number of exceptions in the industry. These exceptions can be investigated using a multi-methodological approach to gather more data from a variety of agencies. These limitations will be further addressed in a $\mathrm{PhD}$ thesis including the possible integration of blockchain to deal with the asymmetric knowledge distribution.

\section{Conclusion}

The focus of this research is on counterbalancing information asymmetry and in particular, the asymmetry that exists in many high-value low- 
frequency transactions. We focus on one type of such transaction, namely the purchase of residential property. We gather information in the context of the New Zealand real estate market and propose a process that attempts to make the tacit, unverifiable knowledge explicit. The presented purchaser decision process model with the division of tacit and explicit information (a) is a building block to address the information asymmetry in the New Zealand real estate industry and (b) presents an opportunity to introduce blockchain technology into the real estate context. By storing all possible explicit information and creating a history of everything that has happened to the asset we will hopefully be able to negate mistakes that can occur to a novice purchaser when purchasing their new home. If we can also use the decision process model as a learning tool to understand the possible questions that could be asked to make an informed decision when buying a property, we can eliminate complications further down the track. We believe our work can be generalised to other high-value infrequently traded assets.

\section{References}

[1] Ackoff, R.L., "From data to wisdom", Journal of Applied Systems Analysis 16(1), 1989, pp. 3-9.

[2] Akerlof, G.A., "The market for 'lemons': Quality uncertainty and the market mechanism", The Quarterly Journal of Economics 84(3), 1970, pp. 488-500.

[3] Alavi, M., and D.E. Leidner, "Knowledge management and knowledge management systems: Conceptual foundations and research issues", MIS Quarterly, 2001, pp. 107-136.

[4] Allmon, D.E., and J. Grant, "Real estate sales agents and the code of ethics: A voice stress analysis", Journal of Business Ethics 9(10), 1990, pp. 807-812.

[5] Argyris, C., and D.A. Schon, Theory in practice: Increasing professional effectiveness, Jossey-Bass, 1974.

[6] Brooking, A., Corporate Memory: Strategies For Knowledge Management, Thompson Business Press, London, 1999.

[7] Carpenter, S., and J. Cannady, "Tool for sharing and assessing models of fusion-based space transportation systems", 40th AIAA/ASME/SAE/ASEE Joint Propulsion Conference and Exhibit, (2004), 3535.

[8] Cleveland, H., "Information as a resource", Futurist
16(6), 1982, pp. $34-39$

[9] Dalkir, K., Knowledge management in theory and practice, Routledge, 2005.

[10] Fahey, L., and L. Prusak, "The eleven deadliest sins of knowledge management", California Management Review 40(3), 1998, pp. 265-276.

[11] Grum, B., and D. Kobal Grum, "A model of real estate and psychological factors in decision-making to buy real estate", Urbani Izziv 26(1), 2015, pp. 82-91.

[12] Harlow, H., "The effect of tacit knowledge on firm performance", Journal of Knowledge Management 12(1), 2008, pp. 148-163.

[13] Hedesstrom, T., and E.A. Whitley, "What is meant by tacit knowledge? Towards a better understanding of the shape of actions", European Conference on Information Systems, (2000), 46-51.

[14] Hevner, A., and S. Chatterjee, Design research in information systems: theory and practice., Springer Science \& Business Media, 2010.

[15] Maltz, E., "Is all communication created equal?: An investigation into the effects of communication mode on perceived information quality", Journal of Product Innovation Management 17(2), 2000, pp. 110-127.

[16] Myers, M.D., Qualitative research in business management, Sage, 2013.

[17] Nonaka, I., and H. Takeuchi, The Knowledge-Creating Company: How Japanese Companies Create the Dynamics of Innovation, Oxford University Press, New York, 1995.

[18] Prendeville, S., and N. Bocken, "Design for remanufacturing and circular business models", Sustainability Through Innovation in Product Life Cycle Design, (2017), 269-283.

[19] Shanon, C.E., and W. Weaver, The Mathematical Theory of Communication, University of Illinois Press, 1949.

[20] Stiglitz, J.E., "The contributions of the economics of information to twentieth century economics", The Quarterly Journal of Economics 115(4), 2000, pp. 1441-1478.

[21] Tuomi, I., "Data is more than knowledge: Implications of the reversed knowledge hierarchy for knowledge management and organizational memory", Hawaii International Conference on Systems Sciences, (1999). 